\title{
Adopting a Mixed Method Needs Analysis for CALL Research
}

\author{
Eunjeong Park ${ }^{1 *}$ \\ ${ }^{1}$ English Language Education, Sunchon National University, 57922 Sunchon, South Korea
}

\begin{abstract}
This paper discusses arguments on necessitating needs analysis with mixed methods in computer-assisted language learning (CALL). CALL researchers argue that a lack of technology integration planning hinders using technology effectively in schools. This would be because teachers may not be wellprepared regarding the use of technology leadership and integration, calling for needs analysis. The purpose of this paper is to examine the definition of needs, potentials and challenges of using mixed methods to develop needs analyses and concludes with the considerations of needs analysis with mixed methods in CALL research.
\end{abstract}

\section{Introduction}

Needs analysis is essential because every course involves specific purposes and different functions in the field of education [1]. Many language researchers have addressed the importance of needs analysis in general [1-7]. West (1994) provided three major roles of needs analysis: 1) improving teaching methods, 2) adapting the teaching to the type of learning public, and 3) training the learner how to learn [2, p. 2]. Hyland (2006) describes needs analysis as a technique for "collecting and assessing information relevant to course design" [3, p. 73]. Flowerdew (2013) has offered a historical overview of needs analysis in English for academic and occupational purposes and appealed to socio-rhetorical genre-analytic and ethnographic needs analysis (JassoAguilar, 2005) and corpus-based methodologies (Biber, 2006) as critical in the field of language learning and teaching [4][8][9].

The field of computer-assisted language learning (CALL) has been growing due to the rapid advancement of technology. Teachers perceive that the use of technology is inevitable in education. Despite the fact that teachers should be ready for the shift of the educational context along with the trend of technology, readiness of this change is not prompt enough to catch up with for teachers. Furthermore, lack of technology leadership and technology integration plans have made teachers feel daunted about what and how to do with technology use. To resolve this issue, the first and foremost thing teachers must do is to acknowledge what learner needs are. In this sense, teachers may be able to implement needs analysis by conducting CALL research.

Teachers are exceptionally situated to offer an insider's view that "makes visible the way that students and teachers together construct knowledge and curriculum" $[10$, p. 43]. In other words, teachers are capable of being reflective of his or her own teaching practice through action research. Action research is a "process that uses collaboration and collective problem solving to change organizations and environments" [11, p. 2]. Thus, action research enables teachers to improve self-reflective inquiry used in professional and curriculum development and school improvement plans [11][12].

Needs analysis is a part of action research that teachers can consider in order to meet students' needs. In the 1970s, Wilkins (1974) developed a notionalfunctional system to develop syllabi and pedagogic materials [13]. This notional-functional approach has been believed to meet a variety of language learning needs in a standardized way. In this prescriptive way, sequences of lexical, structural, notional, and functional language components are pre-planned, assuming that these sequences satisfy learners' needs. However, Long (2005) recognized limitations of heavy reliance on the notional-functional way to understand learners' needs, providing conflicting issues, such as developmental structures in foreign and second language learning (Larsen-Freeman \& Long, 1991) and cognitive processing constrains on learnability and teachability [1][14][15]. However, the prescriptive notionalfunctional approach to assume students' needs is decontextualized, misleading the information about their actual needs. Furthermore, most linguistic analyses are based on the supra-sentential and textual level. For these reasons, Long (2005) proposed a task-based syllabus as a potential needs analysis [1]. Task-based needs analyses are learner-centered, which can be aligned with learners' internal development. Long (2005) conducted an extensive survey of the scholarly literature on needs analysis to identify advantages of using various sources (insiders and outsiders) with the combination of different methods (both qualitative and quantitative) [1].

This paper discusses potentials and controversial issues of mixed methods in conducting CALL research.

* Corresponding author: parkej@scnu.ac.kr 
Sources for needs analyses include scholarly literature, learners, teachers and scholars, domain experts, and triangulated sources. Among them, triangulated sources stand out and can be collected through mixed methods. Triangulation is a way to increase the credibility of the interpretation of qualitative data by comparing two more different sources, methods, researchers, or theories [1][16]. Triangulation of methods may involve different research techniques, such as observation, interviews, questionnaires, and testing within a quantitative paradigm. Because there is the paucity of triangulation in CALL-oriented needs analysis, it is important to involve different sources via mixed methods for learner needs analyses for CALL research.

\section{Definition of Needs}

It may be easy to assume that language courses are necessary and required for college students' career and intellectual development in language education. However, we often disregard what the language course is for. Is a language course really for students or for university? Is this because there is a policy to promote communication skills nationwide? Do learners perceive technology as a medium of language learning? We need to consider the reason for providing language courses and what the benefits of technology use are for students. In this sense, it is essential to identify the necessity of language use for college students in higher education. We should develop syllabus designs and relevant materials aligned with the learner needs. According to Widdowson (1981), the needs may be the present or future requirement of learners, indicating 'the students' study or job requirements, that is, what they have to be able to do at the end of their language course" [17, p. 2]. Mountford (1981) considers needs as what is perceived by the organization or the society in light of language program or instruction [18]. Robinson (1991) refers to needs as lacks of what the students do not know or cannot do in English [19]. Basturkmen (1998) regards language needs as the important consideration to recognize the gap between target proficiency and the present proficiency of learners, which influences the development of curriculum and syllabus designs [20]. Brown (2016) describes the language needs as "sets of judgments and compromises justified by observation, surveys, test scores, language learning theory, linguistics" [21, p. 16]. Needs analysis can function as the systematic investigation of the learner needs for curriculum and syllabus designs in education.

\section{Approaches to Needs Analysis}

The importance of needs analysis has resulted in developing different approaches of conducting needs analysis, leading to the significance of curriculum development. Several influential approaches of needs analysis include: 1) a learning-centered approach, 2) a learner-centered approach, and 3) a task-based approach.

In the 1980s, researchers took a psychological stance to needs towards learning and learners. Hutchinson and
Waters (1987) suggested a learning-centered approach and explained the needs with two directions: target needs and learning needs [22]. Target needs are categorized as necessities, lack, and wants. Berwick (1989) and Brindley (1989) described learner needs with several aspects, such as perceived vs. felt needs, product-oriented vs. process-oriented interpretations, and objective vs. subjective needs [23][24]. An individual's perceptions and interpretations are highlighted in this approach of the needs. Perceived needs are relative to expert orientation, while felt needs are connected to learner orientation [23]. Productoriented interpretations indicate that learner needs are the language required in the target situation; whereas, the focus of process-oriented interpretations relies on how learners affectively and cognitively respond to their learning situations [24]. Lastly, objective needs are different types of factual information about learners, the learners' language use, while subjective needs are about cognitive and affective factors [24]. Objective and perceived needs may come from outsiders, such as teachers and stakeholders; whereas, subjective and felt needs are derived from insiders, i.e., learners. The last one is a task-based approach. The task-based approach formulates needs analysis in the process of teaching and learning. Tasks function as the unit of analysis conceptually and pedagogically in this approach. Successful language use can be understood and evaluated through tasks in the classroom [1]. Tasks enable learners to encompass new language skills with their individual learning styles and personalities [25]. The results of task-based needs analysis can be a source of input for the design of language courses, which can be "harmonized with what language acquisition research has revealed about universal L2 developmental processes in and out of classrooms" [1, p. 23].

\section{Potentials of a Mixed Method Needs Analysis for CALL Research}

Mixed methods research has been recognized as a potentially appropriate research method to encounter the complexity in the levels of multiple data, research designs, and interpretation in education and applied linguistics [26-29]. The term mixed methods research refers to "an intellectual and practical synthesis" [30,p. $129]$ in the process of collecting and analyzing data, integrating the findings, and drawing inferences with the use of both qualitative and quantitative approaches or methods in a single study [26].

Mixed methods research has a lot of potentials, especially aligned with the major goal of research: answering research questions in practice. The inquiry in research can be accomplished through supplementary data from both quantitative and qualitative domains [31]. It embraces the complexity of the data sources and analyses with divergent perspectives. Mixed methods research endorses a focus on the research question with appropriate methods and approaches within a study, positing research in a transformative or transdisciplinary framework by addressing different theoretical and 
methodological perspectives at different levels under the pragmatic paradigm [28][31].

Many researchers have contributed to the development of mixed methods research in the field of education [32-36]. It can broaden the scope of research by layering methodologies across diverse epistemological perspectives [34]. In this sense, needs analysis can be explored with mixed methods by working collectively and collaboratively to solve realworld problems of language learning, including varied epistemological stances. Few articles relative to needs analysis with mixed methods research were found in technology and computer-assisted language learning. Kletzien's (2011) study was a big project about academic English program evaluation using mixed methods [37]. Kletzien (2011) conducted a brief needs analysis to determine international students' and staff's Internet usage habits with a survey questionnaire [37]. Vatanartiran and Karadeniz's (2015) study examined the perceived challenges and needs of integrating technology into the classes for elementary and secondary teachers, which can be used as the needs analysis of technology integration plans [38]. A mixed research design, particularly the triangulation design, was employed for this study. The results of the study revealed that the major issues of technology integration involve executive, infrastructural, and instructional aspects. In addition, technological infrastructure and teachers' technical skills matter the most in the CALL context [38]. O'Reilly (2016) investigated several indicators found in technology needs assessment survey tools, including self-assessed skill level, technology use and integration, teacher beliefs, barriers to access, professional development resources, leadership, needs and wants, and demographics [39]. O'Reilly (2016) asserts that the identification of program needs is the priority of effectively adopting and integrating technology in educational contexts [39]. Poedjiastutie and Rhonda's (2017) study also employed a mixed methods approach with a large-scale survey and focus group discussions to explore EFL students' needs of learning English in Indonesia [40]. A considerable proportion $(42.96 \%)$ of the survey participants indicated their desire to use more sophisticated technology in the language classroom [40].

Triangulating methods for needs analysis is salient in light of credibility and dependability [1]. In addition to the function of triangulation, mixed methods research can provide more channels to conduct needs analyses. Greene, Caracelli, and Graham (1989) proposed five functions of mixed methods designs: (1) triangulation/convergence, (2) complementarity, (3) expansion, (4) development, and (5) initiation [41]. Triangulation/convergence involves the use of both types of methods to answer the same question, either by comparing the results to reach the same conclusion (triangulation or by converting data from one type into another (e.g., quantifying qualitative data or qualifying quantitative data). Complementarity utilizes each set of methods to answer a series of questions for the purpose of elaboration (e.g., using quantitative data for the breadth of understanding and qualitative data for depth of understanding). Expansion indicates using one method to answer questions raised by the other type of method (e.g., using qualitative data to explain the results of quantitative data). Development involves the use of one method for some questions and of the other method for other questions (e.g., developing data collection measures or interventions). Initiation aims at combining quantitative and qualitative methods to uncover paradox and contradiction. Hashemi and Babaii's (2013) study showed a great impact of mixed methods research on new research designs in the field of education [42]. Their findings revealed that a small number of studies reached a high degree of integration of both qualitative and quantitative methods. This study suggests the effective use of mixed methods research as a "versatile research methodology" in the field of education [42, p. 828].

Mixed methods research can be one of the core methods to make needs analysis systematic and rigorous. Mixed methods designs can help us rethink about developing needs analysis not only by triangulating multiple sources but also by complementing, expanding, developing, and initiating them in a tactful way.

\section{Controversies on Using a Mixed Method Needs Analysis for CALL Research}

While we see the value of using mixed methods for needs analysis, there exist some controversial issues and challenges. Johnson and Onwuegbuzie (2004) acknowledged several challenges of mixed methods research [28]. Researchers must learn multiple methods to be able to analyze mixed data with rigor. It is often challenging to interpret conflicting results and analyze quantitative data qualitatively. Incorporating mixed methods may be time-consuming and expensive. It takes relatively longer time to collect and analyze data. Recently, Mirhosseini (2017) has problematized the confusion of the epistemological aspect in mixed methods research [43]. In mixed methods research, objective measurement is in the positivist epistemological position; whereas, contextual meaning making is the aim of qualitative research (Denzin \& Lincoln, 2007) in the interpretivist-constructivist position (Mirhosseini, 2017) [43-45]. Mirhosseini's (2017) claim is that "epistemological incompatibility" $[43$, p. 5] in the recently published research, such as Hashemi's (2012) and Riazi and Candlin's (2014), is not convincing. Mirhosseini (2017) argues that "the choice" [36, p. 143] of an underlying worldview (i.e., pragmatism or critical realism) is problematic, and an actual epistemological foundation for mixed methods research should be introduced. Researchers' cramps of the epistemological foundation of mixing methods are understandable. However, we would argue that learners' needs do not simply emerge with a limited view. The stages of collecting, analyzing, and interpreting data should be layered appropriately for doing the right needs analysis. Mixed methods designs can help discover learner needs in a pluralistic and corroborative way. 


\section{Closing Comments}

Different disciplines, such as health and medical science, engineering education, have advanced their needs analysis with mixed methods research in their fields [46][47]. However, the field of computer-assisted language education and applied linguistics has not yet developed the academic discourse regarding the applicability and practicality of mixed methods for needs analyses. Therefore, we should consider learner needs analysis with mixed methods research as the followings.

First, systematicity of research methods is often neglected in the execution of needs analysis. We should consider the major aspects-the purpose of needs analysis, stakeholders, and multiple sources. An adequate needs analysis requires multiple sources for breadth and depth to an analysis because triangulation of sources generally lead to valid findings. However, we are often too focused on triangulation of sources, which is daunting to engage in mixing methods. Needs analysis can complement, expand, develop, and initiate data for exploring learners' needs. We need to approach developing a needs analysis concurrently or sequentially on a research-based system.

Second, a needs analysis with mixed methods research can help expand fields through capacitybuilding in mixed methods at leading institutions. Learner needs analyses are used by organizations to prioritize needs and make improvements of CALL curriculum and instruction. The quality processes can be assured through comprehensively understanding learner and tracking an evaluation process of curriculum and instruction, accompanied with mixed methods research.

All in all, a carefully sequenced needs analysis with mixed methods contributes to the rigor of CALL-related materials development and course design. Thus, it is important to be cognizant about implementing a needs analysis with mixed methods in a systematic and rigorous way.

\section{References}

1. M. Long, Second language needs analysis (CUP, Cambridge, 2005)

2. R. West, 1994. Needs analysis in language teaching. Lang. Teaching 27, 1 (1994)

3. K. Hyland, English for academic purposes (Routledge, London, 2006)

4. L. Flowerdew, The handbook of English for specific purposes (Wiley-Blackwell, Hoboken, 2013)

5. J.D. Brown, The handbook of language teaching (Wiley-Blackwell, Hoboken, 2009)

6. T. Dudley-Evans, M.J. St John, Developments in English for specific purposes (CUP, Cambridge. 1998)

7. A.M. Johns, L. Makalela, New directions in English for specific purposes research. (UMP, East Lansing, 2011)
8. R. Jasso-Aguilar, Second language needs analysis (CUP, Cambridge, 2005)

9. D. Biber, University language: A corpus-based study of spoken and written registers (John Benjamins, Philadelphia, 2006)

10. M. Cochran-Smith, S.L. Lytle, Inside/outside: Teacher research and knowledge (TCP, New York, 1993)

11. M. Simms, Democ \& Edu 211 (2013)

12. J. McNiff, Action research (Falmer Press, London, 1986)

13. D.A. Wilkins, Linguistic Insights in applied linguistics (AIMAV/Didier, 1974)

14. D. Larsen-Freeman, M. Long, An introduction to second language acquisition research (Longman, London. 1991)

15. M. Pienemann, Language processing and second language development (John Benjamins, Philadelphia, 1998)

16. Y.S. Lincoln, E.G. Guba, Naturalistic inquiry (Sage, Thousand Oaks, 1985)

17. H.G. Widdowson, English for academic and technical purposes (Newbury House, London, 1981)

18. A. Mountford, The way and the way (Longman Group, London, 1981)

19. P. Robinson, ESP today: A practitioner's guide (Prentice Hall, London, 1991)

20. H. Basturkmen, Forum 36, 2 (1998)

21. J.D. Brown, Introducing needs analysis and English for specific purposes (Routledge, New York, 2016)

22. T. Hutchinson, A. Waters, English for specific purposes: A learning-centred approach (CUP, Cambridge, 1987)

23. R. Berwick, The second language curriculum (CUP, Cambridge, 1989)

24. G. Brindley, The second language curriculum. (CUP, Cambridge, 1989)

25. R. White, P. Robinson, RELC Guidelines 17, 93 (1995)

26. J.W. Creswell, V.L. Plano Clark, Designing and conducting mixed methods research (Sage, Thousand Oaks, 2007)

27. K.R. Howe, Edu Researcher 17, 10 (1988)

28. R.B. Johnson, A.J. Onwuegbuzie, Edu Research 33, 14 (2004)

29. A. Tashakkori, C. Teddlie, Handbook of mixed methods in social and behavioral research (Sage, Thousand Oaks, 2003)

30. R.B. Johnson, A.J. Onwuegbuzie, L.A. Turner, J. MMR 1, 112 (2007)

31. C. Teddlie, A. Tashakkori, The SAGE handbook of qualitative research (Sage, Thousand Oaks, 2011)

32. M.R. Hashemi, App. Ling. 33, 206 (2012) 
33. J.H. Hulstijn, R.F. Young, L. Ortega, M. Bigelow, R. DeKeyser, N.C. Ellis, J. Lantolf, A. Mackey, S. Talmy, Stud. Sec. Lang Acq. 36, 361 (2014)

34. K.A. King, A. Mackey, 2016. Modn. Lang. J. 100, 209 (2016)

35. A.M. Riazi, 2016. App. Ling. 37, 33 (2016)

36. A.M. Riazi, C.N. Candlin, Lang. Teach. 47, 135 (2014)

37. J.A. Kletzien, Sec. Lang. Studies 30, 49 (2011)

38. S. Vatanartiran, S. Karadeniz, Contem. Edu. Tech. 6, $206(2015)$

39. E.N. O'Reilly, IJEDICT 12, 129 (2016)

40. D. Poedjiastutiem, O. Rhonda, Eng. Lang. Teach. 10, 124 (2017)

41. J.C. Greene, V.J. Caracelli, W.F. Graham,.Edu. Eval. Policy Analysis 11, 255 (1989)

42. M.R. Hashemi, E. Babaii, Modn. Lang. J. 97, 828 (2013)

43. S.-A. Mirhosseini, TESOL Quart. 52, 468 (2017)

44. J.E.M Sale, L.H. Lohfeld, K. Brazil, Qual. Quant. 36, 43 (2002)

45. N.K. Denzin, Y.S. Lincoln, Collecting and interpreting qualitative materials (Sage, Thousand Oaks, 2007)

46. A.M. Dekker, A.E. Amick, C. Scholcoff, A. Doobay-Persaud, BMC Health Serv. Research 17, 1 (2017)

47. N.O. Ozdemir, Asian ESP J. 15, 98 (2019) 